\title{
A PROPOSED RATING SYSTEM FOR: TOURISTIC COMMUNITIES IN EGYPT
}

\author{
N. DARWISH ${ }^{1}$, G. MOSAAD ${ }^{1} \&$ K. TARABIEH ${ }^{2}$ \\ ${ }^{1}$ Department of Architectural Engineering \& Environmental Design, AAST, Egypt. \\ ${ }^{2}$ The American University in Cairo, Egypt.
}

\begin{abstract}
Rating systems has started to be a tool to manage and asses the performance in many countries in the world. Since the touristic communities are considered one of the critical markets in Egypt, therefore, the reliability of tourism sector requires enough means to improve the performance of these communities. The research objectives is to design a rating system that assist developers to enhance the quality of the existing and planned communities following the guidelines ofsite and urban development, green infrastructure, efficient energy, green transportation and sustainable tourism. The research method is to compare, adapt, and apply the most representative community environment assessment schemes that are in use today. A preliminary studyof six different community rating systems (LEED-ND, Pearl, STAR community, BREEAM, IGBC and GSAS) took placeon the urban level, and followed by analysis and design of a new rating system which is introduced and applied on the city of Sharm EL-Sheikh. The newEgyptian Rating System for Touristic Communities (ERSTC) achieved better environmental, social, and economic performance compared to other rating systems.
\end{abstract}

Keywords: community, rating systems, tourism,touristic cities, touristic communities.

\section{INTRODUCTION}

The purpose of this research is to respond to the emerging needs of sustainable communities through the investigation of a number of rating systems related to sustainable neighborhoods and adapting the knowledge gained to develop a new rating system applicable for Egypt. The research started with a preliminary investigation of commonly used rating systems for buildings and neighborhoods. First a comparative analysis was done between different community rating systems in order to achieve the principles and optimum strategies of a rating system that suits the Egyptian communities. Sustainable community defined as a revised form of self-reliant community development which sustains people's livelihoods using appropriate technology [1]. Second, the paper discussed the flexibility of the communities in touristic cities with the investigation of some examples. In addition, it covers the sustainable development background, the community resilience elements and the role of the local government towards sustainable planning development. The findings of the research suggested that a sustainable community development in the tourist spots will contribute to an improved resilience in the tourism sector. Some strategies are needed to ensure the sustainable development in touristic cities and to sustain the local community resilience and this through the guidance of assessment tools, rating systems combined with the theories of eco neighborhoods to ensure the quality of a livable community. The econeighborhood is a residential or mixed use area around which people conveniently walk. Its scale is geared to pedestrian access [1]. Third part at the end, a comparative table was done between several known rating systems. \footnotetext{
This paper is part of the Proceedings of the $7^{\text {th }}$ International Conference on Sustainable Tourism
(Sustainable Tourism 2016)

CONFERENCES www.witconferences.com
} 
The three previous stages were examined and illustrated in three matrix tables; theories of sustainable communities, Strategies of sustainable tourism and community rating systems analyzed (Figs 1-6) to achieve the new customized community rating system for Egypt.

\section{RESEARCH DESIGN AND METHODOLOGY}

The paper explains the different rating systems and documents a set of recommendations to improve the questioned rating systems of community design and remind designers with the

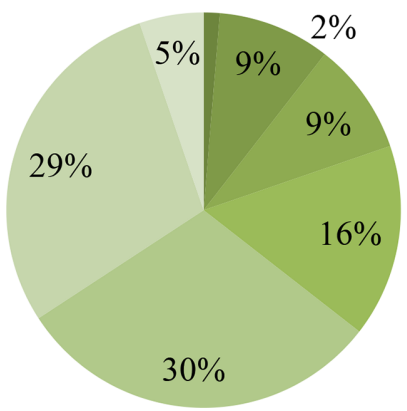

- Site and urban development

- Transportation

Community pattern

- Sustainable tourism

Humans aspect

Energy performance

Extra credits

Figure 1: Comparing categories in the six rating systems. Source: Researcher.
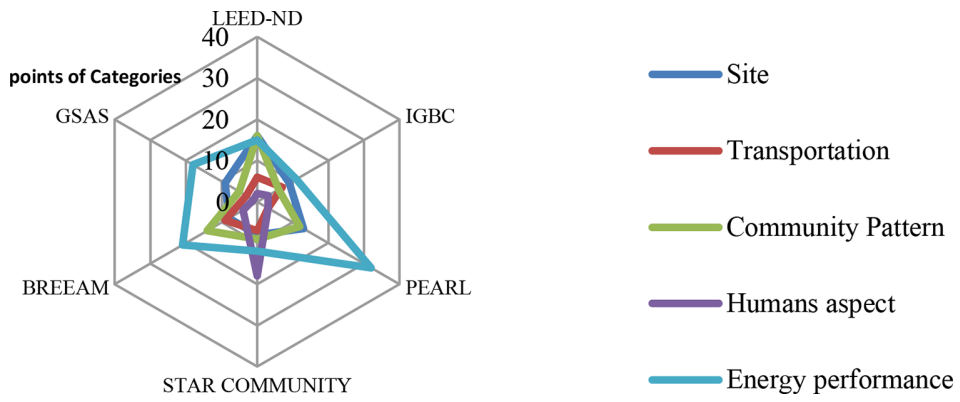

Figure 2: Comparing each criterion inSite\& Urban development.

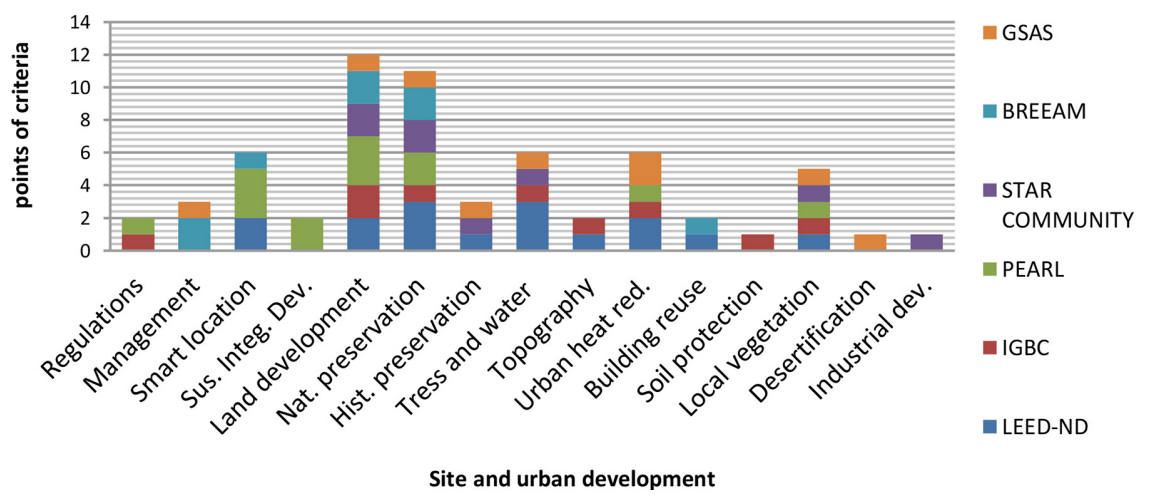

Figure 3: Comparingeach criterion in 'Transportation' in the rating system. 


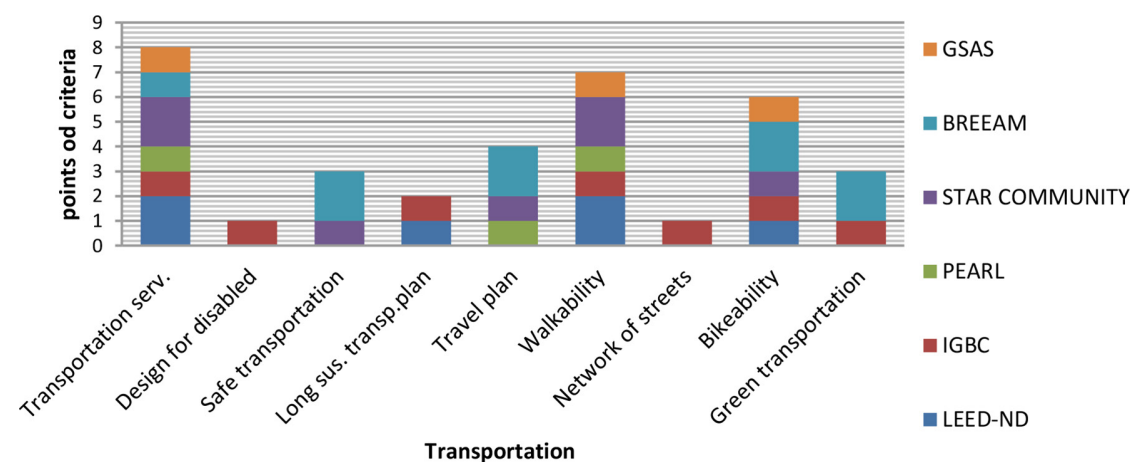

Figure 4: Comparing each criterion in 'Community Patterns'.
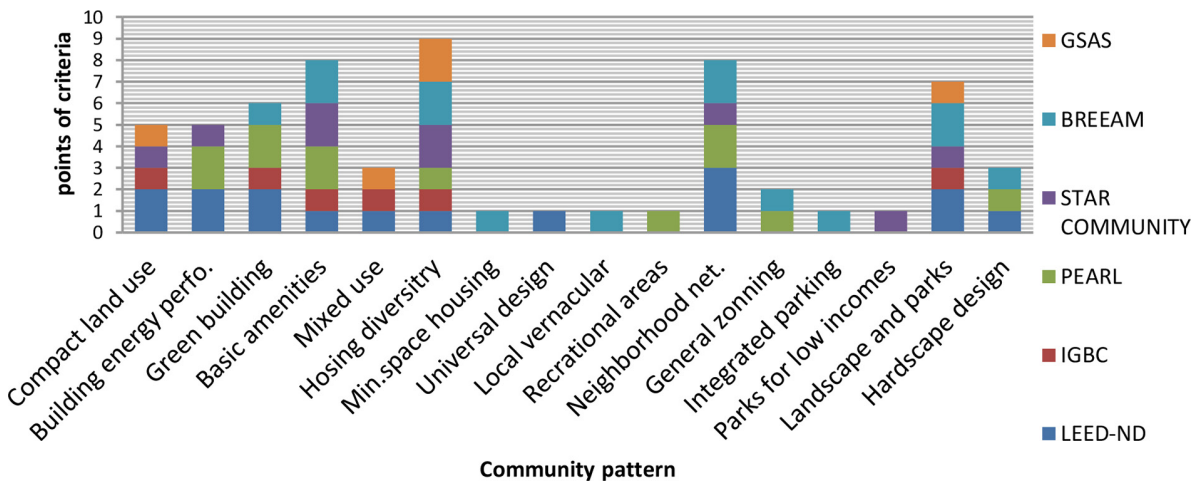

Figure 5: Comparing each criterion in the 'Human aspect' in the rating system.
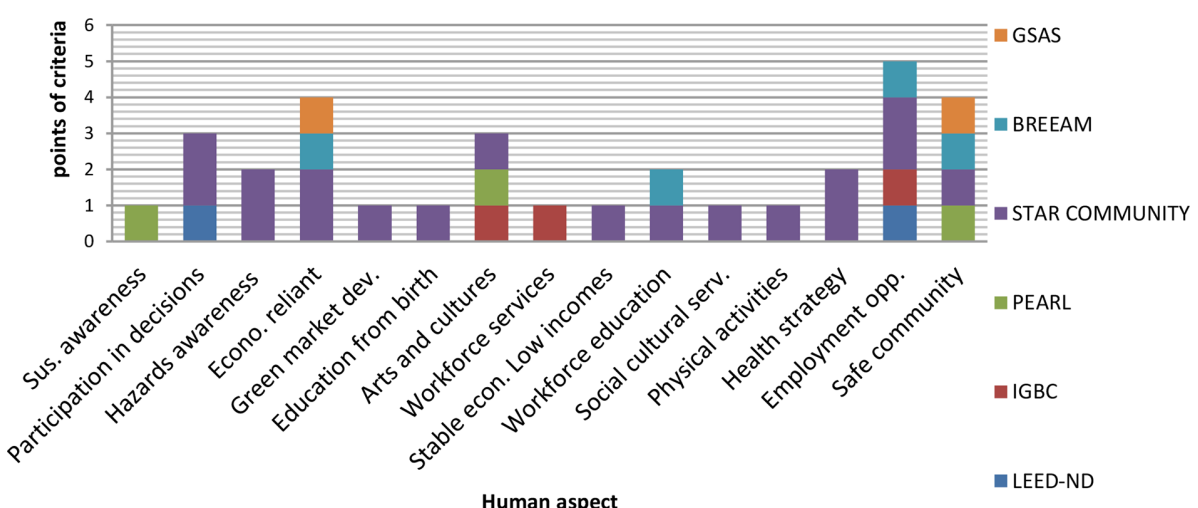

Figure6: Comparing each criterion in 'Energy performance in the investigated Rating systems'.

principles and strategies of sustainable design in urban development that goes beyond the existing rating systems in hot climates. The percentages of distribution of the criterion in each category are presented in (Fig. 7). These are the principles and guidelines used in the matrix table of sustainable communities: 


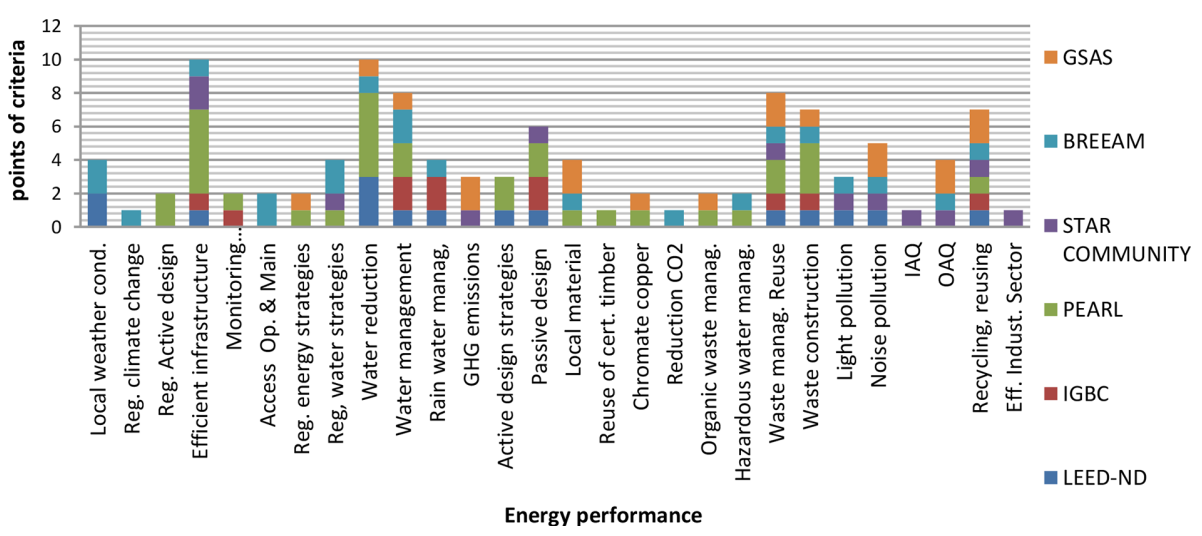

Figure 7: The conclusion of the two Matrix table is analyzed in the following chart. Source: Researcher.

\title{
local significance of the community rating system
}

\author{
Local environmental \\ significance \\ $\square$ Local economic \\ significance \\ $\square$ Local social equity \\ significance \\ $\square$ local touristic \\ significance
}

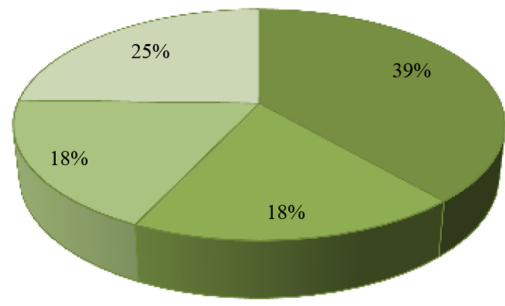

Figure8: Environmental, social, economic, touristic significance of the new customized rating system. Source: Researcher.

- Principles of sustainability

- Department of 'Communities and Local Government'

- Framework of Andres Duany, Elizabeth Plater-Zyberk

- The design features zoning codes of 'Huntersville'

- British design codes

- Greening USA

- The design features of Santa Monica

These are the principles and examples of sustainable tourism used in the second matrix table:

- Guidelines of the sustainable communities in Tanzania

- Iran, an example shows the relationship between tourism and community:

- Principles and guidelines based on the literature review 


\section{STRATEGIES OF SUSTAINABLE COMMUNITIES}

3.1 Achieving sustainability in the community

A great community and neighborhood fabric is built to stand the test of time by responding to its context and climate. It is made up of a range of elements with a fine network of weaving paths and pedestrian-friendly streets throughout to enhance connectivity and encourage walking and cycling. It is easy to navigate and contains open spaces for meeting, relaxing and playing. It contains high quality, sustainable homes that contribute to the identity of the neighborhood. Throughout, facilities are thoughtfully located to meet the needs of the residents. This combination works to create a dynamic, vibrant and cohesive atmosphere [2] the community is also defined as all buildings in a given geographic area, including commercial and residential buildings and a portfolio of buildings dispersed across various geographies but linked by a single owner or set of occupants [3].

\subsection{Traditional neighborhoods}

The traditional neighborhoods typology comprises a compact residential area with a variety of housing types and some supporting service and civic uses like small shops, libraries and churches. It is designed to accommodate pedestrians and public transit as well as travel by car, and like most New Urbanism designers, and New York sociologist Clarence Perry before us, we base the size of neighborhoods on the $1 / 4$ mile measurement as the distance the typical adult can walk from center to edge in approximately $5 \mathrm{~min}$. Completing the circle with this radius creates an area of approximately 125 acres (50 hectares) and comprises about 1000 homes at an average density of 8 dwellings per acre ( 52 persons per hectare). The American neighborhood is different than the European cities as per Perry 5000 residents living in his neighborhood [4].

3.3 Guidance and strategies for connecting several eco neighborhood to achieve sustainable community

Walkable Neighborhood Centers are a fundamental and necessary component of sustainable urbanism, but how we structure them together will ultimately determine the effectiveness of the new urbanism neighborhoods should be clustered to form cities and towns based on transit to deliver on the promise of sustainable development do not segregate community from commerce, as Perry seemed originally to advocate [5].

\section{TOURISM}

\subsection{Relationship between sustainable communities and touristic cities}

Tourism can be seen in 2013 'as a way to aid in generating income for the communities' [6] and so, one of the strategies for the community to achieve better living conditions. The main idea is for the sustainable community is to create a project that presents a sustainable development and promote the relationship between local community and visitors. Sustainable tourism is simply 'the tourism that takes full account of its current and future economic, social and environmental impacts, addressing the needs of visitors, the industry, the environment and host communities' [7]. To develop a tourism product as such, the core characteristic 
is to incorporate hotel management, tourism management, food and beverage and complementary services all together and not to forget other subsystems such as infrastructure, health, education and environment of the community. Therefore, how the whole community partakes in the development of an area is important to widen a tourist destination. This is because tourism planning will affect the whole community. For example, the awareness of tourism is based on the local community's attitude and their evaluation on the environment, infrastructure and events, and the degree of involvement by the local community exerts a strong influence on the tourist's experience [6].

Communities are likely to suffer from traffic congestion, increasing crime rates, waste water generation and increasing cost of living. Although the local population's attitudes toward tourism are important given the argument that a happy community is more likely to support tourism development and welcome tourists. Due to the fact that different communities have different cultures and traditions, tourism development leaves different effects on them. This issue, especially in developing countries, is more important. While most of studies have been conducted from a developed country tourism context, few have been carried out from a developing world perspective. In developing countries, local community participation in the decision making process of tourism development has often been lacking and in the decisionmaking process is always limited or sometimes marginalized. Cater in 1994 highlights the need for local community involvement in planning and managing tourism, particularly in the context of developing countries [8].

In fact, community participation in tourism development does not only relate to the decision making process and the benefits of tourism development, but also regarded integral to sustainable tourism. Community is the most important part, since it is they who will be most affected either positively or negatively by tourism planning and development.[8].

'There is a strong positive relationship between the extent of the community in tourism development and their perceptions towards an increase in tourism development'. Interactions between community and tourists can impact positively in terms of creating opportunities, bringing societal peace, integration of different cultures and negative manners in the form of associated problems. Finally, tourism can improve the quality of life in an area by increasing the number of attractions, recreational opportunities, and services. 'Tourism also offers residents' opportunities to meet interesting people, make friendships, learn about the world, and expose themselves to new perspectives' [8].

\subsection{Community approach to pursue a tourism-based development}

There are several compelling reasons; 'tourism can provide both direct and indirect economic benefits, tourism can generate various social/cultural benefits and tourism can help achieve environmental conservation objectives' [8]. On the other hand tourism can negatively impact communities on all three of these fronts economic, social/cultural and environmental through projects or programs that are poorly designed and implemented without proper planning and consideration of impact result in negative outcomes. Tourism-based development that is too successful may result in undesirable outcomes such as stressing infrastructure limits or causing conflicts between visitor and resident population. Yet despite these concerns, tourism can be a beneficial development strategy for communities when approached correctly. Moreover 'careful planning will allow for future flexibility of new development and revitalization of older tourism areas' [9]. Moreover, successful planning strategy 'goes far beyond schemes to maximize profits and therefore should include a detailed, on the ground outline so as to determine how each of the factors affecting the success of a tourism destination should be 
developed'. In brief, previous literature suggests the following objectives for sustainable tourism development: Formulate a framework to enhance local resident quality of life, develop multiple-use infrastructure and recreational facilities which cater to locals and tourists alike, ensure appropriate developments that are reflective and sensitive to the features unique to the area, take the cultural, social and economic values of the host community into consideration, andoptimize visitor satisfaction [9].

\section{RATING SYSTEMS}

Six community rating systems are compared (Figs1-6) and analyzed in Matrix table and presented in the following charts

The result of proposed community rating system is customized in the table (Appendix A) and then analyzed into local environmental, social and economic significance in (Fig. 8).

\section{DESIGN PROPOSAL FOR A NEW TOURISTIC COMMUNITY RATING SYSTEM IN EGYPT}

\subsection{Site and urban development}

The nine criteria of site and urban development evaluate the environmental effect of new development on existing site. A mandatory criterion to ensure the applicability of the community rating system while improving the coordination between existing and new communities. Also develop the environmental performance of the residents through awareness sessions. To create more livable communities preference should be given to the sustainable integrated design, protect specie, trees, ecological communities and water bodies. In addition, the calculations of heat gain reduction through the limitation of parking lots, streets and non-reflectance surfaces. Ensure that adults and children of all income levels have opportunities to learn about nutritious eating and have physical and economic access to fresh, healthful food.

\subsection{Transportation}

To improve public health and pedestrian environment, eight criteria of this category has shown that living in a mixed-use environment within walking distance of shops and services encourages walking and bicycling, which improve human health and social interaction in the community. Moreover, encourage the use of public transportation to minimize the pollutions and emissions that affect the health, and reduce the traffic congestion. In addition to incorporate public transportation facilities such as metro, buses in a long term transportation plan generated in the next 5-15 years. Ensure the availability of public needs for disabled and encourage the use of renewable energy in public transportations and green vehicles.

\subsection{Community patterns}

The eleven criteria of 'Community Pattern' highlight the creation of compact development, mixed-use neighborhoods with good connections to nearby communities. These vibrant neighborhoods provide many important benefits to residents, employees, and visitors and to the environment. Also to focus the design and development on promoting energy conservation in buildings within the community through the design of high-energy performance integrated buildings. Passive design is required to retrofit to the eco-friendly buildings. Moreover, 
housing typologies and diversity in community is essentially to higher the interaction in social, education and cultural aspects of the residents and from the other hand to protect the community from the rural sprawl of lower incomes. To ensure that the development relates to local character whilst reinforcing its own identity such as building materials, building color, architectural style and building heights and forms is focused in 'local vernacular' criterion.

\subsection{Sustainable tourism}

This category adds novelty to the community rating systems in general, as it combine the principles of sustainable tourism with the major strategies of sustainable communities. This category promotes tourism services in the city through the five criteria to improve the image of the touristic city and improve tourism potential while enhancing the existing livable communities.

\subsection{Human aspect}

Reduce violent crime and increase perceptions of safety are the keys to achieve a safer sustainable community where residents can live in the community protected and feel their children secured. This category evaluates the community in twelve criteria each one of them presents a minor strategy of a human right and aspect. Starting by having an economically self-reliant community where residents are financially independent and feel stable. A complete education system for low and high incomes and expand job opportunities that support upward economic mobility and provide sufficient wages so that working people and their families can afford a decent standard of living. Improve community well-being through participation in local decision-making and volunteering with community organizations. The significant need of social, cultural and arts services that encourage participation and creative self-expression.

\section{6 performance}

'Energy performance' focuses on the environmental consequences of the construction and operation of buildings. The category is divided into 18 criteria as the energy is an essential strategy to reduce pollution and conserve the use of non-renewable and enhance the use of renewable energy in the community such as solar orientation can also reduce energy consumption in buildings through passive or active systems. Applications like photovoltaic systems can be scaled up to neighborhood levels. Moreover, design and maintain a network of green infrastructure features that integrate with the built environment to conserve ecosystem functions and provide associated benefits to human populations. Enable effective long-term decisions about infrastructure design and construction in order to maximize efficiency over the whole life of the development. Metering facilities to measures the performance of infrastructure systems. In addition, integrate comprehensive water strategy during the early stages of design to minimize the overall water consumption. The efficient water in public realm can conserve more water, landscape design through plant selection through irrigation technologies and management, and the use of recycled water. Waste management to reduce the long-term environmental impacts associated with operational waste collection, transport and disposal. Reduce disposal of waste in landfills by proper segregation of waste at source, post-occupancy. Also ensure that indoor air quality is healthy for all people by prohibit smoking in all enclosed public places .Ensure that outdoor air quality is healthy for all segments of the human population and protects the welfare of the community. 


\subsection{Creativity works}

Develop designs that showcase cultural and regional practices, while contributing to the environmental performance of the community. To promote designs that result in a significant positive impact in relation to any of the pillars of sustainability in tourism.

\section{CONCLUSION}

The importance of creating an adaptable sustainable community rating system in Egypt is crucial. Current rating systems are accommodated to suit the environment for which each was designed for. Tourism has long been recognized as a community and economic development strategy as well as one of the fastest growing industries in the world. The research demonstrated that applying an Egyptian-customized sustainable community rating system in touristic cities of Egypt will lead towards a sustainable tourism-based development in the hospitality sector of Egypt as well as improving the performance of residentialcommunities.

\section{RECOMMENDATIONS}

Sharm El-sheikh has great potential to be a sustainable city and the sustainable future development must target the virgin land of Sinai. Moreover, Gouna can be fully developed to a sustainable community, where the new customized rating system of touristic cities in Egypt can be applied there. Investors must take into considerations that they are the key toward any development in the country and their decisions and directions indicate the direction of the next development of the government especially in the tourism sector.

\section{REFERENCES}

[1] Smith, M.K., Sustainable communities and neighbourhoods. theory, policy and practice. The encyclopaedia of informal education. infed, [Online] 2008, [Cited: 30 july 2015.] available at www.infed.org/community/sustainable_communities_and_neighbourhoods.htm

[2] Pearl, Rating system, Neighborhood Planning, Vision 2030, Abu Dahabi: Abu Dahabi urban planning council, 2010.

[3] Net Zero Communities:One Building at a Time, Managan, Katrina, Washington DC: Johnson controls, Institute for Building Efficiency, ACEEE Summer Study, 2012.

[4] Walters, D., Designing Commuity, Oxford: Elsevier, 2007.

[5] Amir, A.F., Ghapar, A.A., Jamal, S.A. \& Ahmad, K.N., Sustainable tourism development: a study on community resilience for rural tourism in Malaysia. Asia Pacific International Conference on Environment-Behaviour Studies, Elsevier: Berlin, pp. 116-122, 2014.

[6] Eshliki, S. \&Kaboudi, M., Community perception of tourism impacts and their participation in tourism planning. ASEAN Conference on Environment-Behaviour Studies, Elsevier: Indonesia, pp. 333-341, 2011.

[7] UNWTO, sustainable development of tourism, united nation world tourism organization. sdt. unwto,. [Online] [Cited: 9 April 2016.]available at http://sdt.unwto.org/content/about-us-5

[8] Chhabra, D. \& Phillips, R., Tourism-based development. An Introduction to Communiyt Development, P. Rhonda, P. Robert, Routledge: New York, pp. 236-265, 2009.

[9] Jones, E., slide share. Austarlian council for new urbanism. Optimizing Urban Structure: Toward an Integrated New Urbanist Model. [Online] 2016.[Cited: 15 October 2015.]available at available at http://www.slideshare.net/CNU17/optimizing-urbanstructure-toward-an-integrated-new-urbanist-model-evan-jones-cnu-17 
Appendix A: Proposed customized community rating system

\begin{tabular}{lll}
\hline Site and urban development & \\
\hline Mandatory & Consultation plan and management & Required \\
Mandatory & Desertification & Required \\
Mandatory & Land development & Required \\
SUD 1 & Sustainable integrated development & Credit \\
SUD 2 & Natural preservation & Credit \\
SUD 3 & Historical preservation & Credit \\
SUD 4 & Historical preservation & Credit \\
SUD 5 & Urban heat island & Credit \\
SUD 6 & Local vegetation and food production & Credit \\
\hline Transportation & & \\
\hline Mandatory & Long term transportation plan & Required \\
Mandatory & Walkability & Required \\
Mandatory & Transportations facilities and services & Required \\
T1 & Bikeability & Credit \\
T2 & Design for different able and seniors & Credit \\
T3 & Safe and affordable transportations & Credit \\
T4 & Network of streets & Credit \\
T5 & Green transportations and services & Credit \\
\hline
\end{tabular}

Community patterns

\begin{tabular}{lll}
\hline Mandatory & Building energy performance & Required \\
Mandatory & Basic amenities and services & Required \\
Mandatory & Mixed use & Required \\
CP 1 & Compact development & Credit \\
CP 2 & Housing affordability and diversity & Credit \\
CP 3 & Local vernacular & Credit \\
CP 4 & Neighborhood connectivity & Credit \\
CP 5 & Recreational urban areas & Credit \\
CP 6 & Parks and open spaces for low-incomes & Credit \\
CP 7 & Landscape areas and parks & Credit \\
CP 8 & Hardscape area and modular pavement & Credit \\
\hline Sustainable tourism & & \\
\hline Mandatory & Guest information desks & Required \\
Mandatory & Local traditional industrial & Required \\
ST1 & Connectivity between attractions and hotels & Credit \\
ST2 & Green star hotels & Credit \\
ST3 & Education and tourism development program & Credit
\end{tabular}




\begin{tabular}{|c|c|c|}
\hline \multicolumn{3}{|c|}{ Human Aspect } \\
\hline Mandatory & Sustainability awareness & Required \\
\hline Mandatory & Safety and security & Required \\
\hline HW 1 & Economically self-reliant community & Credit \\
\hline HW 2 & Green market development & Credit \\
\hline HW 3 & Education from birth to adulthood & Credit \\
\hline HW 4 & Participation in local decision making & Credit \\
\hline HW 5 & Arts and cultures services & Credit \\
\hline HW 6 & Social and cultural initiatives & Credit \\
\hline HW 7 & Stable economic for low incomes & Credit \\
\hline HW 8 & Employment opportunities & Credit \\
\hline HW 9 & Physical activities & Credit \\
\hline HW 10 & Health strategy to reduce hazards & Credit \\
\hline \multicolumn{3}{|c|}{ Energy performance } \\
\hline Mandatory & Regional strategies and active design & Required \\
\hline Mandatory & Efficient infrastructure & Required \\
\hline Mandatory & Monitoring infrastructure energy & Required \\
\hline EP1 & Access to operation and maintenance & Credit \\
\hline EP2 & Regional energy strategies & Credit \\
\hline EP3 & Regional water strategies & Credit \\
\hline EP4 & Water reduction for public realm & Credit \\
\hline EP5 & Green house gas $\mathrm{CO} 2 \mathrm{emission}$ reduction & Credit \\
\hline EP6 & Renewable energy and passive design & Credit \\
\hline EP7 & Local material & Credit \\
\hline EP8 & Organic waste management & Credit \\
\hline EP9 & Waste management and reuse & Credit \\
\hline EP10 & Indoor waste segregation & Credit \\
\hline EP11 & Light pollution & Credit \\
\hline EP12 & Noise pollution & Credit \\
\hline EP13 & Indoor air quality & Credit \\
\hline EP14 & Outdoor air quality & Credit \\
\hline EP15 & Recycling and reusing & Credit \\
\hline \multicolumn{3}{|c|}{ Creative Works } \\
\hline CW1 & innovative cultural and regional practices & Credit \\
\hline CW2 & innovating sustainability practices & Credit \\
\hline
\end{tabular}

